\title{
Ultrasound B scan: a simple tool to simplify the diagnosis
}

\author{
Amar Pujari, Jayanand Sudhakar Urkude, Vaishali Rakheja, Gunjan Saluja
}

Department of Ophthalmology, Dr. Rajendra Prasad Centre for Ophthalmic Sciences, AllMS New Delhi, India

\section{Correspondence to} Dr Amar Pujari, dramarpujari@gmail.com

Accepted 25 May 2017

\section{DESCRIPTION}

Case 1: Posterior segment ultrasonography for a patient with total cataract shows a well defined mushroom-shaped mass arising from the choroid with underlying excavation. Surrounding choroid was normal; the dimensions were $6.9 \mathrm{~mm}$ in basal diameter and $9.3 \mathrm{~mm}$ in vertical height. As the ultrasonic waves pass through the mass there is progressive decrease in amplitude of the wave due to the homogeneous mass inside known as 'Positive angle kappa' (figure 1A). These findings are typically suggestive of a medium-sized choroidal melanoma.

Case 2: Similarly, ultrasound in a case following penetrating trauma revealed thick well defined semicircular mounts extending from the ciliary body region to the equator is suggestive of 'Kissing choroidal detachment' subsequent to suprachoroidal haemorrhage (figure $1 \mathrm{~B}$ ) . In contrast, the retinal detachment will be a moderate-to-high amplitude membrane spike extending from the peripheral retina till the optic nerve head.
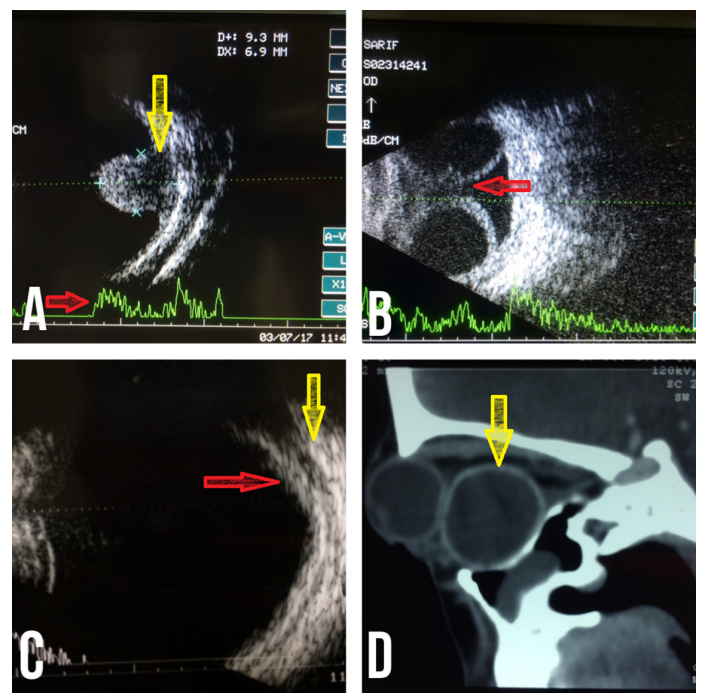

Figure 1 (A) A well defined mass arising from the choroid having a high amplitude initial spike followed by progressive decline in the size of the amplitude (known as positive kappa angle) (red arrow) along with underlying choroidal excavation (yellow arrow) suggests choroidal melanoma. (B)Dome shaped, broad mounts extending from the periphery till the equator touching each other at the centre suggests a kissing choroidal detachment (red arrow). (C) Large cystic cavity showing two layers in the walls known as 'double wall sign' (red and yellow arrows) in a case of orbital hydatid cyst. (D) CT showing a large well defined cystic cavity in the inferior orbital cavity (yellow arrow).
Case 3: A 40-year-old woman with progressive proptosis in the left eye for the past 1 year revealed anechoic posterior segment. Orbital examination showed a well defined empty cystic cavity with two thick layers of its wall known as 'Double wall signs' (figure 1C). Subsequently CT of the orbit shows a well defined rounded cystic mass inferior to the globe, (figure 1D) suggestive of orbital hydatid cyst, which was subsequently confirmed after surgical excision.

Ophthalmic ultrasound is a very important tool for the assessment of ocular and orbital pathology. Many a time choroidal melanomas are diagnosed on ultrasound for an exudative retinal detachment, vitreous haemorrhage or anterior segment opacity evaluation. Under such circumstances with suspicious mass, eliciting the proper signs along with a keen observation of the waveform (progressive decrease in the amplitude of the waveform followed by a high scleral spike), choroidal excavation beneath the mass, collar stud appearance and hypoechoic inner mass is necessary. Basal as well as apical dimensions are also necessary as these parameters also help in classifying the melanoma as small, medium or large sized for treatment and prognosis.

Choroidal detachment is a devastating consequence or complication following surgery/trauma. Well defined, semicircular, broad, choroidal mounts extending from the ciliary body to equator are generally seen in suprachoroidal haemorrhage. Similarly, these lesions can appear at the posterior pole depending on the location of the pathology. Ultrasonography is the best tool for diagnosis as well as serial monitoring for resolution of the same before doing any surgical drainage. ${ }^{1}$ Orbital hydatid cyst is not uncommon in developing countries; the diagnosis depends on eliciting the relevant history in endemic areas followed by ultrasonography which usually shows a cystic cavity along with a typical double wall sign in the presence of hydatid sand attached to the walls. ${ }^{2}$ Ultrasound is an easy, reliable tool for diagnosing many more ocular disorders in a short period of time which provides very good findings in an outpatient as well as in an ocular emergency set-up.

Contributors AP, JSU, VR and GS have evaluated the educational value of these images with an important clinical lesson. All the authors have contributed to writing of this report.

Competing interests None declared.

Patient consent Obtained.

Provenance and peer review Not commissioned; externally peer reviewed. 


\section{Learning points}

- Ultrasound is an effective initial screening tool to ease the diagnosis in common ocular conditions, which every ophthalmologist should be well versed with.

- With careful observation towards wave pattern and amplitude spike a conclusive diagnosis can be ascertained in many of the posterior segments and orbital diseases. (c) BMJ Publishing Group Ltd (unless otherwise stated in the text of the article) 2017. All rights reserved. No commercial use is permitted unless otherwise expressly granted.

\section{REFERENCES}

1 Verma L, Venkatesh P, Chawla R, et al. Choroidal detachment following retinal detachment surgery: an analysis and a new hypothesis to minimize its occurrence in high-risk cases. Eur I Ophthalmol 2004:14:325-9.

2 Betharia SM, Sharma V, Pushker N. Ultrasound findings in orbital hydatid cysts. Am J Ophthalmol 2003;135:568-70

Copyright 2017 BMJ Publishing Group. All rights reserved. For permission to reuse any of this content visit http://group.bmj.com/group/rights-licensing/permissions.

BMJ Case Report Fellows may re-use this article for personal use and teaching without any further permission.

Become a Fellow of BMJ Case Reports today and you can:

- Submit as many cases as you like

- Enjoy fast sympathetic peer review and rapid publication of accepted articles

- Access all the published articles

- Re-use any of the published material for personal use and teaching without further permission

For information on Institutional Fellowships contact consortiasales@bmjgroup.com

Visit casereports.bmj.com for more articles like this and to become a Fellow 